\title{
Setting Realistic Expectations and Possible Career Pathways for Junior Health Professionals
}

\author{
Richard J. Barohn, Professor/Vice Chancellor for Research \\ Kim S. Kimminau Professor, Family Medicine Research Division \\ William M. Brooks, Professor/Director, Hoglund Brain Imaging Center \\ University of Kansas Medical Center
}

$\mathrm{S}$ upporting career decision-making in healthcare and health sciences is enhanced when options are mapped and described. Laying out pathway options, describing expectations coupled with likely outcomes that highlight research, teaching, entrepreneurism and business options are useful for both junior health professionals and mentors.

Career path direction decisionmaking is a challenge for many young healthcare professionals. ${ }^{1-4}$ Lent et al. use a social cognitive framework to understand three linked aspects of career development: (a) the formation and elaboration of career-relevant interests, (b) selection of academic and career choice options, and (c) performance and persistence in educational and occupational pursuits. ${ }^{5}$ Social cognitive career theory supports the notion that self-efficacy informs career choices, ${ }^{4}$ but a central issue remains that exposure to career pathway options and more importantly, clarity on what factors contribute to success once on those paths, remain elusive for many young health professionals. Offering realistic expectations early in career choice decision-making is essential to ensure cost- and time-effective investment for both the individual health professional and the system in which they seek career growth.

Providing a roadmap approach to career options that lay out opportunities, goals and expectations for health professionals with $\mathrm{MD}, \mathrm{DO}$ and $\mathrm{PhD}$ degrees may be of utility for mentors, individual scholars and others seeking to support young faculty. While career decision-making is multifactorial and driven by unique individual and environmental factors, the figures and tables included here have proved useful heuristic tools for mentees and health professionals as they graduate and consider career options. The choices made will determine the expectations or possibilities of having research as part of their work.

\section{Opportunities and Career goals for MDs/DOs}

Graduates from medical school have a variety of career options. ${ }^{6}$ They need to decide if they want to join a practice in an academic setting or a nonacademic setting (Figure 1). If they chose a non-academic practice, then the decision is if they should join a private practice or a health system practice. The proportion of U.S. graduates planning full-time clinical practice careers has declined to about $50 \%$ which is attributable to graduates' preference for part-time clinical practice, demographic factors and debt. ${ }^{6}$ As private practice models are rapidly disappearing from the American medical landscape, employment in health systems and in alternative settings is expanding. Private practice does remain an option for some $\mathrm{MD} / \mathrm{DO}$ graduates, often depending on 
geographic location. A private practice can either be as a solo practitioner or with a small number of other physicians or with a larger multi-specialty group practice. In this setting, it is possible to be involved in research activities, especially as part of industry-sponsored pharmaceutical trials. Some private practitioners can devote a considerable amount of their time to industrysponsored trials. The motivation is to both be on the cutting edge of biomedical research and to be able to offer their patients new drug trials. Because income can be generated from being involved in the trials, participation may be costneutral or even positive. However, participation in industry-sponsored trials usually cannot be done when physicians are just beginning their career. It usually takes some time for the physician to be recognized as an expert in a particular area and for pharmaceutical companies to identify them as a potential site leader for a trial. Once involved in trials, if one is successful (i.e., the physician is able to recruit participants and report data as required), the opportunities increase. It is possible although not common for physicians in a private practice setting to do their own investigator-initiated trials (IIT), and to be a site for other's IIT studies once they are recognized as leaders in the field. Finally, while publishing in the private practice setting is not needed for career advancement, it is certainly an option for those interested in being part of the discovery process.

Physicians in the non-academic model can join a health care system to practice medicine as shown in Figure 1.

Figure $1 . \mathrm{MD} / \mathrm{DO}$ career and practice pathways

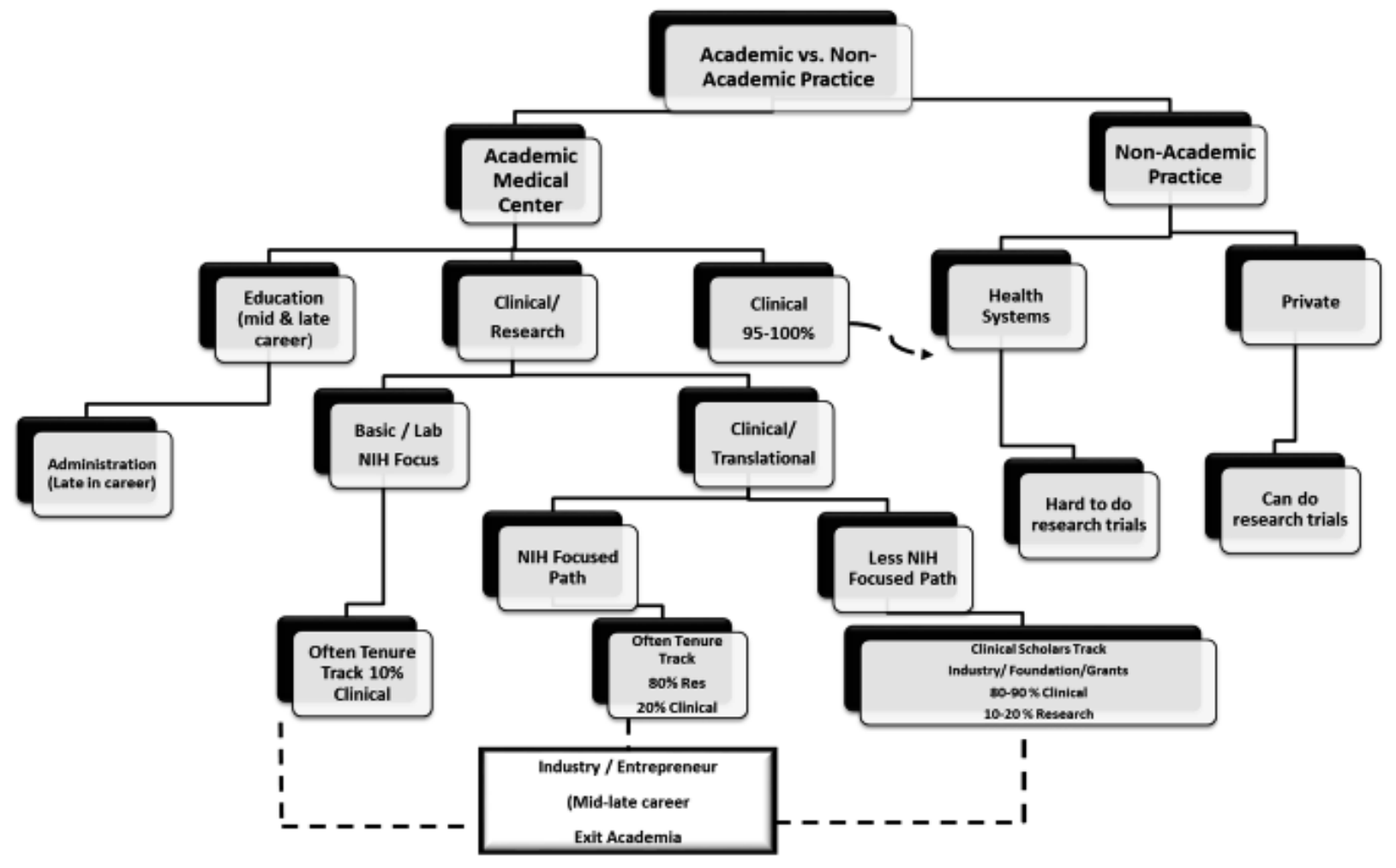


This can be a for profit or not for profit system. This is rapidly becoming the dominant practice location and model in the United States. ${ }^{6}$ Depending on the health care system, it can be difficult or easy to get involved in clinical trials and research. In fact, some systems allow and encourage involvement in research. But others hire physicians exclusively to be involved in clinical income generating activity and they discourage or prohibit physicians from participating in clinical trials as it takes their time away from their revenue goal. If a decision is made to join an academic medical center (AMC), usually affiliated with a university, then there are more options. One option is to see patients and do only clinical work. This is analogous to those in a health care system that do only clinical activity, and it is difficult but not impossible for physicians on this pathway to get involved in research. Their chances for involvement in research are a bit higher than for physicians at a for profit or not for profit health system. Some physicians at an AMC get one half day a week off for "administrative time" which can also be used for "discovery time." This can allow involvement in writing cases or perhaps being an investigator or collaborator in a clinical trial. These physicians are usually on what is called a "clinical track" and they do not receive startup money for research endeavors when they are hired, nor do they get protected time to conduct research.

If the physician is on a hybrid clinical and research track, then there are several options. One is the path of a "classic" physician - laboratory scientist who has a wet lab research focus. For these physicians, the goal is to obtain $\mathrm{NIH}$ and other funding to support their work. Usually these physician scientists spend no more than one half to one day a week in clinic and the rest of their time is dedicated to pursuing research. This is invariably a tenure track position. An emerging path that is becoming more common involves physicians who want to pursue a career in clinical and translational research that does not have a wet lab component. These physicians are involved in in depth clinical study of a disease or health area that can lead to $\mathrm{NIH}$ clinical intervention trials. To be successful on the clinical/translational research path with the goal to obtain $\mathrm{NIH}$ or other funding requires the same amount of research effort as the classic physician scientist in a wet lab. Both the laboratory-based and non-lab physician scientist require startup packages when they are hired to be successful. These packages will usually carry an investigator for two or three years and by that time they are expected to have secured funding to support themselves and their team members.

The last pathway depicted in Figure 1 allows research time for a physician is often called the clinical scholar track and this is probably the most common pathway at most universities for physicians. These physicians, while primarily seeing patients, decided to join an AMC so they could be involved in the discovery and research enterprise at some level. These are not wet lab based physicians but rather their research pursuits are usually in the realm of clinical translational projects. If these physicians desire to be involved in discovering more about patients' diseases and health, presenting data at meetings, publishing papers or being involved in clinical trials, this pathway provides such options. Their clinical practice generates most of their salary, with lesser contribution from grant funding. Some of them eventually do their own investigator initiated 
studies at their local university, but these can expand with external funding to multicenter clinical projects. This group represents most of university physician faculty. It is a challenge for them to able to find sufficient time needed to engage in discovery activities because of their busy clinic schedules. University leadership and mentors need to be creative in helping to make time for conducting research. These physicians can begin by getting into a clinical trial research (usually initially an industrysponsored study). Over time, as their reputation grows as an academic physician in a certain area, they then get invited to be in more and more trials, including being a site leader for an $\mathrm{NIH}$ clinical trials led by colleagues at other universities. With enough experience in these endeavors (along with concomitant publications, presentations and grant writing opportunities) some faculty can successfully write their own NIH or comparable funded study.

Financing Time for Research in an Academic Health Center

With each level of involvement in research activities the faculty member is encouraged to bring in some research dollars that can essentially "buy themselves out" of some of their clinical activity. The goal of some of these clinical scholars is to start with perhaps a day off a week when they first get hired to do discovery research activities. This amount of time off from clinical activity needs to be supported by the university and the department. If research funding results, then the faculty may be able to create more freedom from clinic responsibilities. Some clinical scholars over time can eventually be 50 percent clinical and 50 percent research. These faculty are usually not on a tenure track, but again this is very university dependent. When a clinical scholar is first hired they generally do not get any large degree of startup funds or protected time other than a day a week. Sometimes the young clinical scholar can request a portion of an existing clinical research coordinator's time if they anticipate getting involved in trials immediately. The expectation is that within a year or two they would be supporting a portion of the research coordinator's effort out of the revenue generated from research income and eventually they could support a full-time coordinator of their own.

Figure 1 also shows that some physicians over time can gravitate to other endeavors in a university involving education or administration. In addition, physicians who have had some experience doing research, either in the lab or clinical translational research, can exit to work for industry or to become entrepreneurs and begin their own startup companies.

\section{What is Expected?}

Table 1 describes what sorts of scholarly activity and goals physicians who plan to do some degree of research should be striving for at various stages of their career. (Many of these milestones apply to PhDs, and some specific activities germane to their career development are included.) While not comprehensive, Table 1 includes some of the potential grant mechanisms and funding sources that are geared for health professionals as their career grows. 


\begin{tabular}{|c|c|c|c|}
\hline \multicolumn{2}{|l|}{ AGE } & GRANTS/FUNDING & $\begin{array}{l}\text { ACADEMIC } \\
\text { RANK } \\
\text { Med Students }\end{array}$ \\
\hline $\begin{array}{l}\text { Late } 20 \text { 's - Early } \\
30 \text { 's } \\
\text { - Case Reports } \\
\text { - Case Series } \\
\text { - QAVI } \\
\text { - Publish } \\
\text { dissertation- } \\
\text { related } \\
\text { paper(s) } \\
\text { - Present } \\
\text { research at } \\
\text { local, } \\
\text { regional, } \\
\text { national } \\
\text { meetings } \\
\text { - Seek } \\
\text { opportunities } \\
\text { to publish with } \\
\text { mentor and } \\
\text { others }\end{array}$ & $\begin{array}{l}\text { Complete Degree; } \\
\text { defend dissertation } \\
\text { - Obtain Boards }\end{array}$ & $\begin{array}{ll}- & \text { Med Students } \\
& \text { TL1 / T32 } \\
\text { - } & \text { Residents/Fellows } \\
& \text { R 25/T32 } \\
& \text { Foundations } \\
\text { - } & \text { Pre-doctoral } \\
\text { MD/PhD } \\
\text { select F, K, R and } \\
\text { T awards }\end{array}$ & $\begin{array}{l}\text { Med Students } \\
\text { Residents } \\
\text { Fellows } \\
\text { Doctoral } \\
\text { Candidates }\end{array}$ \\
\hline $\begin{array}{l}\text { Mid 30's - Early } \\
40 \text { 's } \\
\text { - Establish } \\
\text { mentor team } \\
\text { - Write abstracts } \\
\text { - Review papers } \\
\text { - Write } \\
\text { Measurement } \\
\text { /Endpoint } \\
\text { papers } \\
\text { - Conduct meta- } \\
\text { analyses } \\
\text { - Review/Criteria } \\
\text { papers } \\
\text { - Conduct } \\
\text { follow-up } \\
\text { dissertation- } \\
\text { related } \\
\text { studies }\end{array}$ & $\begin{array}{l}\text { - Get in pharma trials } \\
\text { - Get in disease } \\
\text { group consortium } \\
\text { trials } \\
\text { - Use expertise to } \\
\text { augment disease } \\
\text { focused or } \\
\text { population focused } \\
\text { studies } \\
\text { - Intensify national } \\
\text { networking } \\
\text { - Obtain MSCR, } \\
\text { MPH, MBA } \\
\text { - Join } \\
\text { interdisciplinary } \\
\text { teams/"do" } \\
\text { team science } \\
\text { - Branch into } \\
\text { additional } \\
\text { research } \\
\text { topical areas }\end{array}$ & $\begin{array}{l}\text { Career development } \\
\text { awards } \\
\text { - } \quad \text { NIH K23, K08, } \\
\text { K01,CTSA, KL2, } \\
\quad \text { F05, F30, VA } \\
\text { - } \quad \text { Foundations } \\
\text { - } \quad \text { Institutional Pilots } \\
\text { - } \quad \text { R03, R21 }\end{array}$ & $\begin{array}{l}\text { Assistant } \\
\text { Professor } \\
\text { Postdoctoral } \\
\text { Fellow }\end{array}$ \\
\hline \multicolumn{2}{|c|}{$\begin{array}{l}\text { Mid 40's } \\
\text { - Investigator Initiated Trials (IIT) - single } \\
\text { site, small, pilot } \\
\text { - Ask/collaborate to be in other's multisite } \\
\text { IITs, esp. NIH/PCORI } \\
\text { - Serve as a reviewer; get on a study } \\
\text { section }\end{array}$} & $\begin{array}{ll}\cdot & \text { NIH R21/R01 } \\
& \text { Foundation } \\
\cdot & \text { CTSA KL2 } \\
\cdot & \text { VA Merit } \\
\cdot & \text { More Institutional } \\
& \text { grants }\end{array}$ & $\begin{array}{l}\text { Associate } \\
\text { Professor }\end{array}$ \\
\hline
\end{tabular}




\begin{tabular}{|c|c|c|}
\hline $\begin{array}{l}\text { - Begin mentoring students/trainees/junior } \\
\text { faculty } \\
\text { - Increase number of first author } \\
\text { publications }\end{array}$ & & \\
\hline $\begin{array}{l}\text { Late } 40 \text { 's - Early 50's } \\
\text { - Initiate multicenter IIT - 1st pharma, } \\
\text { then federal } \\
\text { Initate or expand into international } \\
\text { networks if appropriate } \\
\text { Continue publishing and increase } \\
\text { number of high impact journal } \\
\text { publications }\end{array}$ & $\begin{array}{ll}\text { - } & \text { NIH RO1/FDA } \\
& \text { lother Federal } \\
\text { - } & \text { Patient Centered } \\
& \text { Outcomes } \\
& \text { Research Institute } \\
\text { (PCORI) } \\
\text { - } \quad \text { Industry } \\
\text { - } & \text { Philanthropy }\end{array}$ & $\begin{array}{l}\text { Professor; } \\
\text { Department Chair }\end{array}$ \\
\hline $\begin{array}{l}\text { Mid } 50 \text { 's } \\
\text { - Lead a consortium/program project } \\
\text { - No more abstracts; increase number of } \\
\text { - } \text { - Write a book } \\
\text { - Serve as a journal editor } \\
\text { - Lead an NIH or other study section } \\
\text { - Continue to connect to mentees as they } \\
\text { move ahead in their careers }\end{array}$ & $\begin{array}{l}\text { NIH U and P awards } \\
\text { Limited or no } \\
\text { institutional grants }\end{array}$ & $\begin{array}{l}\text { Professor; } \\
\text { Endowed Chair }\end{array}$ \\
\hline $\begin{array}{l}\text { - Late } 50 \text { 's - Early 60's } \\
\text { - Start a website/Organization } \\
\text { - Stop reviewing (or be selective) } \\
\text { - } \quad \text { Accept invitations to travel and lecture } \\
\text { more nationally/internationally } \\
\text { - Focus on supporting mentees by } \\
\text { reviewing their work (see above in } \\
\text { younger cohort(s)) }\end{array}$ & Raise more money & $\begin{array}{l}\text { Distinguished } \\
\text { Professor; } \\
\text { Ex-Chair } \\
\text { - Research } \\
\text { - Administration }\end{array}$ \\
\hline $\begin{array}{l}\text { - Mid - Late 60's \& 70's } \\
\text { - Serve as Board Member/ Academic } \\
\text { Society Leader }\end{array}$ & $\begin{array}{l}\text { Continue to raise } \\
\text { money and support } \\
\text { research and } \\
\text { institutional mission }\end{array}$ & Retire /Emeritus \\
\hline
\end{tabular}

Table 1. Select typical activities and milestones for research health professionals by decade. 
When physicians are in medical school, residency and fellowship (20's and early 30's) their focus is to get their degree and pass board examinations. Scholarly activity during early career years can be case reports and case series. Some medical students have some laboratory research experience and a small number begin their training on the $\mathrm{MD} / \mathrm{PhD}$ pathway which is much more research focused. Some grant programs exist to allow a medical student to do a year of research and obtain a Master of Public Health or a Master of Science in Clinical Research (M.S.C.R.) while in medical school. There are some NIHsupported grant programs to university departments that encourage residents and fellows to spend concentrated time on research.

If a physician joins an AMC after fellowship training, the amount of time spent on research of course depends on the track and career path he chooses as described above. In general, this is the time as an assistant professor that is spent writing abstracts to present to national meetings and to be visible academically. This will lead to getting into industrysponsored trials and other consortium trials. Some junior faculty can pursue a M.S.C.R. over a number of years if they are interested in a research career. All faculty at this early stage can apply for institution-sponsored pilot grants for projects. The physicians on a NIH focused pathway need to apply for career development grants (K22 for clinical research/ K08 for laboratory research).

Having obtained some research success as an assistant professor is important to result in promotion to the associate professor level. At this point it is possible to embark on one's own investigator initiated clinical trials and he will more frequently be asked to be on colleagues' IIT multicenter trials from around the country. NIH-focused physicians need to be obtaining their own independent funding beyond the career development grant level and the goal is to ultimately obtain an R01 grant. At the professor level one has the experience and leverage to develop, obtain funding for, and run a multicenter IIT. This can happen before one reaches this career point but it is a reality that often this does not happen until one is well into their 40s. It takes time and experience to get proficient at this type of complicated clinical and translational research activity. This is a time for significant networking, including possible international collaboration. It may become easier due to reputation and research accom plishments to obtain large grants from industry and philanthropy to do IITs. When one enters the later years of an academic career, one can pursue larger funded projects such as complex center and multicenter awards. Applying for local institutional pilot grants is best left to more junior faculty at this point. Career pathway decisions remain crucial and opportunities may arise in research administration which can limit continued research discovery. Finally, tension between continuing the pursuit of research success and associated satisfaction with decisions to retire come into play.

\section{PhDs in Health and Healthcare}

Whatever their intentions when students enroll in graduate school, career pathways are often molded by immersion in the graduate school culture. ${ }^{7}$ Unlike the educational pathway that results in an $\mathrm{MD} / \mathrm{DO}$, graduate students may recognize that earning a Master's degree in programs such as business, public health, education, and 
social work, may lead to health-related career opportunities that they seek, and they may stop there with their higher education. ${ }^{8}$ Deciding to pursue a doctoral degree hinges on a relatively long term commitment to study in a specific field of choice. That singular decision - to seek a degree in chemistry, biology, anatomy, sociology, engineering, etc.- sets the first, pivotal step on the path to career development and career options. After obtaining a doctoral degree, some graduates continue in training as postdoctoral fellows in an academic setting, but this is highly variable depending on the field of study. Some academic disciplines have a long tradition of offering postdoctoral fellowships while in others, such training is rare. For PhDs, acquiring a job in academia is considered the highest form of success (especially as the competition for tenure-eligible positions is finite and competition for those limited positions is fierce). Doctoral candidates often are urged to have a "Plan B" to find a position in the non-academic world. By considering this a fallback option, such planning communicates that working in an alternative setting like in a health system or as staff supporting the conduct of research is less prestigious and less desirable (even if it might be more lucrative). Focusing on doctoral-level biomedical science graduates, a recent study suggested that students who choose nonacademic careers may be perceived as simply leakage from the desired pipeline, a metaphor that perpetuates the negative perception that these scientists represent failure. ${ }^{9}$ This bias is changing, and biomedical and behavioral sciences researchers are encouraged to seek research positions outside of academia. ${ }^{10}$

Beyond a traditional faculty appointment in academia, other options include positions as a non-tenure track research assistant professor or a nonfaculty position as a research scientist. Some doctoral graduates can move into the field of clinical trials research as study staff personnel (i.e., project manager/director) on a clinical research team. There also are jobsin the regulatory management of the clinical trials enterprise in the research offices that support the clinical research teams. 

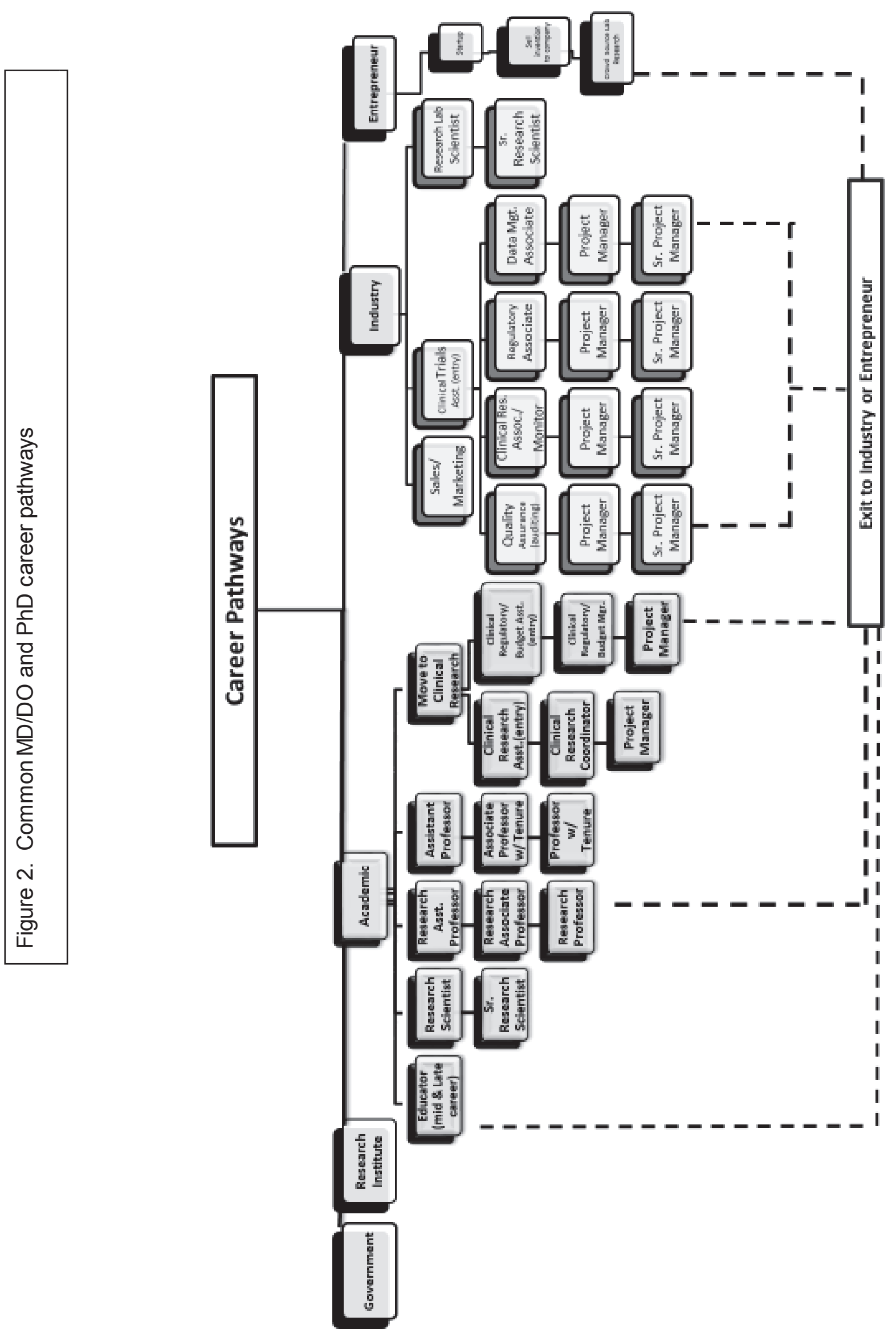
Some career pathways for $\mathrm{PhDs}$ are comparable to or the same as pathways for MDs/DOs. Figure 2 depicts five career options that health professionals may follow. While the connections appear linear, some health professionals move between options over the course of their careers, and sometimes back again. Career pathways can be fluid, but generally health professionals' training and personal preference determine the sphere in which they prefer to practice, teach, conduct research or develop/invent health-related enterprises.

One option open to both clinicians and PhDs is in laboratory and biomedical or health research that is done at freestanding, non-university research institutes. For example, working for a Clinical Research Organization (CRO) can provide a young career $\mathrm{PhD}$ the opportunity to explore their interests in the management and conduct of clinical trials. Some PhDs go directly into industry and there are a variety of job opportunities in this realm. One can continue to work in the wet lab as a research scientist or one can move into the field of pharmaceutical clinical trials in which there are several roles including quality assurance, clinical research associate and then clinical research monitor, regulatory associate and data management. Doctoral trained professionals also can find health and healthcare career opportunities working for or leading health-related nonprofit organizations, serving in community health and service organizations, public health (local, regional and state agency) and for think tanks/policy institutes. All these pathways can over time lead to research-related project leadership as well as publication opportunities., At any point in time, a doctoral trained professional can exit the academic, nonprofit or industry world and become an entrepreneur.

Summary and Words of Advice

No matter if one is a MD, DO or $\mathrm{PhD}$, the pursuit of a career in research and discovery can be very rewarding on many levels. The motives to pursue such a career path range from altruistic (helping humanity), practical (you need a job) to narcissistic (to feel important). Regardless of the motive, successful researchers excel generally at networking early in their career, getting their name visible by presenting their science at academic meetings and working in a team science environment. Working in isolation is not a path for success; all of the pathways depend on the ability to collaborate, negotiate win-win solutions and persistence.

Using all available resources to make research successful is crucial. Finding a good mentor and nurturing a mentor team over time is very important. Finding a long-distance mentor(s) outside of the individual's institution or company can be equally important for long-term career success. These mentors bring objectivity and a novel network of colleagues who may be instrumental in building on a career path. It is also important to connect with patients and patient organizations who are involved in the disease /health area being studied. Getting them involved early and often in research projects and asking them what type of research needs to be done in the field can be illuminating and rewarding.

\section{Write, Write, Write!}

Unless junior professionals publish research findings, the likelihood of a long, successful research career diminishes. If candidates do not have publications to put on their $\mathrm{CV}$, they will have great difficulty getting grants funded or in being promoted. Early on, writing abstracts, case reports, methodology papers and dissertation- 
related papers is advisable. Write the early results and do not neglect writing negative data and negative trials. Write review papers, too, as these frequently get cited and they focus attention on emerging expertise which leads to recognition of the professional as a thought leader in the field. Pivotal papers are important but no one should wait for the "big one." Continuing to steadily publish builds reputation, and even less impactful papers are valuable along the way. As the young professional develops, it is advisable to have several active projects going at the same time. This diversifies the individual's research portfolio and provides multiple opportunities to publish with different teams on different aspects of research interests. If a paper is rejected from a first-tier, high impact journal, do not abandon the paper but instead, seek publication in another journal. In this regard, open access publications have value, but seek guidance from mentors given the emergence of predatory open access journals. ${ }^{11-13}$ Review all options to make scholarship and research findings known, including using earned media from your institution or company to highlight the work. Do not pass up the opportunity to present research at local, regional and national meetings or to use growing relationships to patient and community-based organizations to share findings. Building momentum and working to maintain momentum by writing, publishing, presenting and partnering are keys to success for all the pathways described.

\section{Acknowledgement:}

This work was supported by a CTSA grant from NCATS awarded to the University of Kansas for Frontiers: University of Kansas Clinical and Translational Science Institute (\# UL1TR002366). The content is solely the responsibility of the authors and does not necessarily represent the official views of the NIH or NCATS. 
References Cited

1. Kavanaugh J, Duffy JA, Lilly J. The relationship between job satisfaction and demographic variables for healthcare professionals. Management Research News. 2006;29(6):304-325.

2. Mechaber HF, Levine RB, Manwell LB, Mundt MP, Linzer M, Investigators $M$. Part-time physicians... prevalent, connected, and satisfied. J Gen Intern Med. 2008;23(3):300-303.

3. Prystowsky JB, Bordage G. An outcomes research perspective on medical education: the predominance of trainee assessment and satisfaction. Medical Education. 2001;35(4):331-336.

4. Bakken LL, Byars-Winston A, Wang M-f. Viewing clinical research career development through the lens of social cognitive career theory. Advances in Health Sciences Education. 2006;11(1):91-110.

5. Lent RW, Brown SD, Hackett G. Toward a unifying social cognitive theory of career and academic interest, choice, and performance. Journal of vocational behavior. 1994;45(1):79-122.

6. Jeffe DB, Andriole DA, Hagem an HL, Whelan AJ. The changing paradigm of contemporary US allopathic medical school graduates' career paths: Analysis of the 1997-2004 national AAMC Graduation Questionnaire database. Academic medicine. 2007;82(9):888-894.

7. Golde CM. The formation of scholars: insights of the Carnegie Initiative on the Doctorate. GeoJournal. 2015;80(2):209-213.

8. Wendler C, Bridgeman B, Cline F, et al. The Path Forward: The Future of Graduate Education in the United States. Educational Testing Service. 2010.

9. Fuhrmann CN, Halme D, O'sullivan P, Lindstaedt B. Improving graduate education to support a branching career pipeline: recommendations based on a survey of doctoral students in the basic biomedical sciences. CBE-Life Sciences Education. 2011;10(3):239-249.

10. National Academies of Sciences E, Medicine, Initiative CotNG. The Next Generation of Biomedical and Behavioral Sciences Researchers: Breaking Through. National Academies Press; 2018.

11. Beall J. Criteria for determining predatory open-access publishers. Scholarly open access. 2015.

12. Beall J. Medical publishing triage-chronicling predatory open access publishers. Annals of Medicine and Surgery. 2013;2(2):47-49.

13. Shen C, Björk B-C. 'Predatory'open access: a longitudinal study of article volumes and market characteristics. BMC medicine. 2015;13(1):230. 